\title{
Successfully Treating Hypercalcemia Secondary to Subcutaneous Fat Necrosis With Pamidronate: A Case Series
}

\author{
Ryan J. Dyess ${ }^{\mathrm{a}, \mathrm{c}}$, Prasanthi Pasala Gandham ${ }^{\mathrm{b}}$, Bradly J. Thrasher ${ }^{\mathrm{b}}$
}

\begin{abstract}
Subcutaneous fat necrosis (SCFN) is an unusual source of hypercalcemia in neonates. This condition is self-limiting; however, hypercalcemia can occur as a sequela. Severe hypercalcemia can result in increased morbidity and mortality. Several modalities of treatment for hypercalcemia subsequent to SCFN have been explored, including the use of bisphosphonates, particularly pamidronate. We briefly review SCFN, recognition of this uncommon dermatological phenomenon, as well as hypercalcemia resultant from SCFN and its current management strategy. Furthermore, we report a case series of two patients treated successfully with intravenous pamidronate in conjunction with other treatment modalities.
\end{abstract}

Keywords: Subcutaneous fat necrosis; Pamidronate; Hypercalcemia; Bisphosphonates

\section{Introduction}

Subcutaneous fat necrosis (SCFN) is a known but uncommon cause of hypercalcemia in neonates. SCFN usually presents in the first several weeks of life with subcutaneous nodules which are described as painful, erythematous and indurated being either red, brownish, or violaceous in color [1]. Although this condition is self-limiting, hypercalcemia secondary to SCFN can be severe and result in serious sequelae such as seizures, cardiac arrest, renal failure and death. Prompt diagnosis and treatment is warranted to reduce morbidity and mortality [1].

The following cases highlight the importance of early rec-

Manuscript submitted November 3, 2020, accepted November 16, 2020

Published online March 19, 2021

${ }^{a}$ University of Louisville School of Medicine, Louisville, KY, USA

bUniversity of Louisville School of Medicine, Norton Children's Hospital, Louisville, KY, USA

${ }^{\mathrm{c} C o r r e s p o n d i n g ~ A u t h o r: ~ R y a n ~ J . ~ D y e s s, ~ D i v i s i o n ~ o f ~ P e d i a t r i c ~ E n d o c r i n o l o g y ~}$ Academic Office, University of Louisville School of Medicine, 571 S. Floyd Street, Ste. 106, Louisville, KY 40202, USA.

Email: ryan.dyess@louisville.edu

doi: https://doi.org/10.14740/ijcp420 ognition, initial management and referral for SCFN. General pediatricians have a strong role in diagnosis as neonates can present to their general practitioners without obvious risk factors. Our two cases highlight how early recognition allowed for early referral and treatment as well as the importance of pamidronate in treatment of hypercalcemia secondary to SCFN.

\section{Case Reports}

\section{Case 1}

A 5-week-old male infant presented for failure to thrive and subcutaneous nodules. He was born at 39 weeks gestation to a 24-year-old G2P2 mother with gestational diabetes and preeclampsia via cesarean section due to breech positioning and nonreassuring fetal heart tones. There was no other relevant family medical history or medical concerns in his sibling. He was large for gestational age with a birth weight of 4,510 g, length of $52.1 \mathrm{~cm}$ and head circumference of $37 \mathrm{~cm}$. Apgars were 1 at $1 \mathrm{~min}$ and 7 at $5 \mathrm{~min}$, respectively. Delivery was complicated by meconium aspiration and difficult extraction. He required admission to the neonatal intensive care unit (NICU) for hypoglycemia and thrombocytopenia, which was diagnosed as neonatal alloimmune thrombocytopenia and responded to intravenous immunoglobulin (IVIG). He was discharged home at 11 days of life with close hematology follow-up.

On day 16 of life, his mother initially noticed a small red nodule below his sternum. He developed more subcutaneous nodules and had poor weight gain; therefore, he was eventually referred to our hospital after several visits to his pediatrician. On arrival, the patient was well appearing, but there were multiple subcutaneous nodules felt throughout the upper abdomen, chest, axilla, arms and back. Several nodules had overlying erythema. Otherwise he had an unremarkable physical exam and normal vital signs. Labs were obtained (Table 1) which revealed an initial calcium of $16.8 \mathrm{mg} / \mathrm{dL}$, parathyroid hormone $(\mathrm{PTH})$ was $<3.4 \mathrm{pg} / \mathrm{mL}$, urine calcium to creatinine ratio was $2.13,25$-hydroxy $(25-\mathrm{OH})$ vitamin D was $18.3 \mathrm{ng} /$ $\mathrm{mL}$ and 1,25-dihydroxy $(1,25-\mathrm{OH})$ vitamin $\mathrm{D}$ was $235.5 \mathrm{pg} /$ $\mathrm{mL}$. Triglycerides were elevated at $589 \mathrm{mg} / \mathrm{dL}$. Electrocardiogram (EKG) on arrival showed no arrhythmias.

Patient was diagnosed with hypercalcemia secondary to SCFN. He was initially treated with intravenous hydration at 
Table 1. Initial Laboratory Values

\begin{tabular}{llll} 
& Case $\mathbf{1}$ & Case 2 & Reference range \\
\hline Serum calcium & $16.8 \mathrm{mg} / \mathrm{dL}$ & $13.8 \mathrm{mg} / \mathrm{dL}$ & $8.6-11.2 \mathrm{mg} / \mathrm{dL}$ \\
Phosphorus & $5.4 \mathrm{mg} / \mathrm{dL}$ & $5.4 \mathrm{mg} / \mathrm{dL}$ & $4.9-8.9 \mathrm{mg} / \mathrm{dL}$ \\
Magnesium & $1.6 \mathrm{mg} / \mathrm{dL}$ & $1.9 \mathrm{mg} / \mathrm{dL}$ & $1.6-2.3 \mathrm{mg} / \mathrm{dL}$ \\
PTH & $<3.4 \mathrm{pg} / \mathrm{mL}$ & $<3.4 \mathrm{pg} / \mathrm{mL}$ & $11.5-82.7 \mathrm{pg} / \mathrm{mL}$ \\
Urine calcium to creatinine ratio & 2.13 & Not obtained & $20.0-100.0 \mathrm{ng} / \mathrm{mL}$ \\
25-hydroxy vitamin D & $18.3 \mathrm{ng} / \mathrm{mL}$ & $18.4 \mathrm{ng} / \mathrm{mL}$ & $19.9-79.3 \mathrm{pg} / \mathrm{mL}$ \\
1,25-dihydroxy vitamin D & $235.5 \mathrm{pg} / \mathrm{mL}$ & $127.0 \mathrm{pg} / \mathrm{mL}$ & $35-291 \mathrm{mg} / \mathrm{dL}$ \\
Triglycerides & $589 \mathrm{mg} / \mathrm{dL}$ & Not obtained & \\
\hline
\end{tabular}

PTH: parathyroid hormone.

1.5 maintenance rate, subcutaneous calcitonin $4 \mathrm{U} / \mathrm{kg}$ q $12 \mathrm{~h}$ for four doses which was decreased to $2 \mathrm{U} / \mathrm{kg}$ q $12 \mathrm{~h}$ for two doses and low calcium formula. However, after these treatments failed to completely resolve his hypercalcemia, he received a total of two doses of intravenous (IV) pamidronate $0.5 \mathrm{mg}$ / $\mathrm{kg} /$ dose on consecutive days. During this time, other therapies were weaned and eventually discontinued as calcium level normalized. Within $48 \mathrm{~h}$ after second dose of pamidronate, patient's calcium level decreased to $9 \mathrm{mg} / \mathrm{dL}$. Calcium remained normal $48 \mathrm{~h}$ after all therapies were discontinued. His calcium level was monitored regularly after discharge (Table 2) and remained normal. Subsequently, his nodules have decreased in size during this time period as well.

\section{Case 2}

A 4-week-old female infant presented for evaluation of hypercalcemia and suspected SCFN from her pediatrician's office. She was born at 39 weeks gestation to a 20-year-old G1P1 mother with unremarkable prenatal labs and pregnancy via spontaneous vaginal delivery without complications. There was no relevant family medical history. She had a birth weight of $3,848 \mathrm{~g}$, length of $53.3 \mathrm{~cm}$ and head circumference of $35.5 \mathrm{~cm}$. Apgars were 3 at $1 \mathrm{~min}$ and 7 at $5 \mathrm{~min}$, respectively. The neonate experienced prolonged head-to-body delivery time which required additional force to dislodge the baby's shoulder. However, no instrumentation was reported as being used. A nuchal cord was present after delivery. Nonetheless, the neonate did not experience meconium aspiration or other significant birth trauma and otherwise had an unremarkable postnatal course.

At approximately 2 weeks of age, the family noted nodules on the infants left upper arms and trunk. She was evaluated by her pediatrician who was astutely concerned for SCFN. Her examination was otherwise unremarkable and she had normal vital signs. A calcium was obtained which was normal at 10.7 $\mathrm{mg} / \mathrm{dL}$ at that time, but the patient was noted to have thrombocytosis of $703,000 / \mu \mathrm{L}$. She was seen 10 days later for concerns for constipation and irritability where a calcium increased to $12.6 \mathrm{mg} / \mathrm{dL}$. Serial calcium levels were monitored by her pediatrician, and by 4 weeks of age, her calcium had risen to 13.8 $\mathrm{mg} / \mathrm{dL}$. She also continued to be irritable and was not tolerating her formula despite several changes to the formula.
After admission labs were obtained (Table 1) which showed a suppressed PTH of $<3.4(11.5-82.7 \mathrm{pg} / \mathrm{mL})$ as well as an elevated 1,25-OH vitamin D of 127.0 (19.9 - $79.3 \mathrm{pg} / \mathrm{mL})$. These results were consistent with SCFN. No imaging studies were obtained. She was placed on IV fluids at 1.5 maintenance rate. However, despite hyperhydration for approximately $24 \mathrm{~h}$, there was no improvement in clinical status, nor in her calcium level from admission. Therefore, she was treated with a onetime dose of pamidronate $0.25 \mathrm{mg} / \mathrm{kg}$. She tolerated the infusion without any adverse events or side effects.

Roughly $24 \mathrm{~h}$ after administration, her calcium began to decrease and stabilized 2 days after administration at $9.8 \mathrm{mg} /$ dL. Her calcium was monitored overnight and remained stable at that level. Her calcium continued to be monitored regularly after discharge (Table 2) and remained stable since administration of pamidronate. Her nodules decreased in size during that time period as well. She did not require any additional medical treatment or formula changes (low calcium formula).

\section{Discussion}

In the cases presented, both patients were diagnosed with Table 2. Follow-Up Calcium Values

\begin{tabular}{lll}
\hline & Case 1 & Case 2 \\
\hline On admission & 16.8 & 13.8 \\
\hline 1 day after admission & 13.0 & 13.0 \\
\hline 2 days after admission & 13.2 & 11.8 \\
\hline 3 days after admission & 10.6 & 9.8 \\
\hline 6 days after admission & 8.8 & 9.7 \\
2 weeks after admission & 10.7 & 9.9 \\
\hline 3 weeks after admission & 10.6 & 10.4 \\
4 weeks after admission & 10.5 & 10.1 \\
\hline 6 - 7 weeks after admission & 10.2 & 10.6 \\
\hline months after admission & $\mathrm{n} / \mathrm{a}$ & 10.4 \\
\hline 5 months after admission & 10.7 & 11.2 \\
\hline
\end{tabular}

All values are in $\mathrm{mg} / \mathrm{dL}$ with reference range of $8.6-11.2 \mathrm{mg} / \mathrm{dL}$. 
hypercalcemia secondary to SCFN and had successful treatment and recovery with pamidronate. The two cases can be compared to illustrate the importance of early recognition of this condition to allow for appropriate monitoring, initial management and referral. The cases presented a unique diagnostic conundrum in which patients presented to their pediatricians without obvious neonatal incidents predisposing them to SCFN. In the cases, they both had trauma which upon recall from parents occurred during the birthing process. Additionally, in case 1, the patient experienced meconium aspiration but did not require extensive respiratory support. These likely contributed to the development of SCFN. Thus, it underscores the importance of recognition based on a thorough and full history and physical examination.

SCFN is a self-limiting panniculitis that develops within the first 6 weeks of life of term infants who usually have experienced significant traumatic events [1]. The exact incidence is not known; however, with an increase in infants receiving cooling protocols and being born to diabetic mothers, the incidence of this dermatological process will likely increase. The exact mechanism behind the formation of the nodules is unknown. However, a few proposed mechanisms have been formed based on known risk factors for SCFN which include: hypoxic ischemic injury, meconium aspiration, sepsis, Rh incompatibility, hypothermia/cooling protocols, birth trauma and maternal factors such as gestational diabetes mellitus and preeclampsia [2-4]. SCFN often spontaneously resolves without dermatological sequelae within weeks to months [1]. Nevertheless, while the nodules are present and up to 6 months after they dissipate infants can be at risk for complications. The most common complication arising in approximately $50 \%$ of infants with SCFN is hypercalcemia [5]. Additional complications include thrombocytosis, hypertriglyceridemia and hypoglycemia but are more rare than hypercalcemia [1].

Hypercalcemia resulting from SCFN can be asymptomatic or present with a variety of different symptoms. Therefore, it is possible that if the diagnosis of SCFN is not made clinically that subsequent hypercalcemia could go unnoticed. Neonates can present with irritability, poor feeding, dehydration, vomiting, lethargy and hypotonia $[1,3]$. Hypercalcemia will present in infants with SCFN within 60 days of the appearance of the nodules in $95 \%$ of patients [5].

The pathogenesis of hypercalcemia related to SCFN is not completely understood. However, it has been demonstrated that elevated levels of 1-alpha-hydroxylase exist in the granulomatous cells in SCFN [6]. The 1-alpha-hydroxylase converts the $25-\mathrm{OH}$ vitamin $\mathrm{D}$ to $1,25-\mathrm{OH}$ vitamin $\mathrm{D}$ which causes calcium to release from bones and increases calcium absorption from the gut. There have been other proposed mechanisms which include increased prostaglandin $\mathrm{E}$ or parathyroid hormone; however, when levels of those hormones are obtained, they are usually normal [1]. Another postulation includes decreased renal clearance of calcium, thus leading to elevated serum calcium levels [1].

The preferred initial treatment for hypercalcemia related to SCFN is hyperhydration, although the rate of hyperhydration is not described in literature [1-3, 6-10]. Additionally, low calcium formula has been used successfully. Case series have also demonstrated that bisphosphonate therapy is a safe and efficacious first-line therapy for hypercalcemia secondary to SCFN, and one that is well tolerated [7]. Possible side effects of bisphosphonate therapy include: an acute "flu-phase" reaction with fever, myalgia, bone pain, vomiting and hypocalcemia [8]. However, a review of literature demonstrates that one to four total doses of bisphosphonates at $0.25 \mathrm{mg} / \mathrm{kg} / \mathrm{dose}$ to $0.5 \mathrm{mg} / \mathrm{kg} / \mathrm{dose}$ has successfully treated hypercalcemia related to SCFN without causing major adverse side effects $[7,8]$.

Pamidronate can also forestall the need for other medical treatments which have a host of well-described side effects. Several papers have suggested decreased length of stay when comparing pamidronate to other treatment options [7, 8]. Alternative treatment options that are sometimes considered and used include furosemide, calcitonin and steroids. Furosemide can lead to dehydration, additional electrolyte disturbances and nephrocalcinosis. Steroids generally take longer to work, can also lead to nephrocalcinosis and also place that patient at unnecessary risk of iatrogenic adrenal insufficiency [7]. Lastly, calcitonin is often associated with tachyphylaxis and only provides short term decrease in calcium before it becomes less efficacious.

\section{Learning points}

SCFN is an uncommon and overall benign dermatological diagnosis that results in hypercalcemia in half of diagnosed cases. Certain traumatic neonatal events predispose infants to developing SCFN though the pathogenesis is incompletely understood. Primary care providers in particular must be aware of complications associated with SCFN as prompt evaluation and treatment are important to ensure adverse outcomes are avoided. Through our two cases and a review of literature, we have found that pamidronate was an efficacious and safe option for treatment of hypercalcemia related to SCFN. Considering that SCFN can take weeks to months to resolve, pamidronate was chosen to help ameliorate need for further treatment considering the long duration of effect that bisphosphonates produce.

\section{Acknowledgments}

None to declare.

\section{Financial Disclosure}

This manuscript received no funding or financial support.

\section{Conflict of Interest}

None to declare.

\section{Informed Consent}

\author{
Not applicable.
}




\section{Author Contributions}

Dr Dyess was the primary author. Dr Thrasher and Dr Pasala Gandham both reviewed and edited the content of the manuscript.

\section{Data Availability}

The data supporting the findings of this study are available from the corresponding author upon reasonable request.

\section{References}

1. Hunt R. Subcutaneous fat necrosis of the newborn. UpToDate. November 27, 2019. Available at: www.uptodate. com. Accessed March 31, 2020.

2. Hicks MJ, Levy ML, Alexander J, Flaitz CM. Subcutaneous fat necrosis of the newborn and hypercalcemia: case report and review of the literature. Pediatr Dermatol. 1993;10(3):271-276.

3. Tran JT, Sheth AP. Complications of subcutaneous fat necrosis of the newborn: a case report and review of the literature. Pediatr Dermatol. 2003;20(3):257-261.

4. Burden AD, Krafchik BR. Subcutaneous fat necrosis of the newborn: a review of 11 cases. Pediatr Dermatol. 1999;16(5):384-387.

5. Stefanko NS, Drolet BA. Subcutaneous fat necrosis of the newborn and associated hypercalcemia: A systematic review of the literature. Pediatr Dermatol. 2019;36(1):2430.

6. Farooque A, Moss C, Zehnder D, Hewison M, Shaw NJ. Expression of 25-hydroxyvitamin D3-1alpha-hydroxylase in subcutaneous fat necrosis. Br J Dermatol. 2009;160(2):423-425.

7. Chesover AD, Harrington J, Mahmud FH. Pamidronate as first-line treatment of hypercalcemia in neonatal subcutaneous fat necrosis: A case series. Paediatr Child Health. 2021;26(1):e52-e56.

8. Samedi VM, Yusuf K, Yee W, Obaid H, Al Awad EH. Neonatal hypercalcemia secondary to subcutaneous fat necrosis successfully treated with pamidronate: a case series and literature review. AJP Rep. 2014;4(2):e93-96.

9. Verma S, Bailey SM, Mally PV, Wachtel EV. Subcutaneous fat necrosis and hypercalcemia after therapeutic hypothermia in patients with hypoxic-ischemic encephalopathy: a case series. Cureus. 2018;10(7):e3074.

10. Shumer DE, Thaker V, Taylor GA, Wassner AJ. Severe hypercalcemia due to subcutaneous fat necrosis: presentation, management and complications. Arch Dis Child Fetal Neonatal Ed. 2014;99:F419-F421. 